Research Article

\title{
Determining the Seepage Stability of Fractured Coal Rock in the Karst Collapse Pillar
}

\author{
Tianjun Zhang, ${ }^{1}$ Mingkun Pang $\mathbb{D}^{1}{ }^{1}$ Xiufeng Zhang, ${ }^{2}$ and Hongyu Pan ${ }^{1}$ \\ ${ }^{1}$ College of Safety Science and Engineering, Xi'an University of Science and Technology, Xi'an 710054, China \\ ${ }^{2}$ College of Science, Xi'an University of Science and Technology, Xi'an 710054, China \\ Correspondence should be addressed to Mingkun Pang; 1063862886@qq.com
}

Received 2 December 2019; Revised 21 May 2020; Accepted 2 July 2020; Published 25 July 2020

Academic Editor: Xiaodong Hu

Copyright $(2020$ Tianjun Zhang et al. This is an open access article distributed under the Creative Commons Attribution License, which permits unrestricted use, distribution, and reproduction in any medium, provided the original work is properly cited.

\begin{abstract}
The karst collapse pillar (KCP) is a common geological structure in the coal mines of northern China. KCPs contain many fractured coal rocks, which can easily migrate under the action of high-pressure water. The destruction or instability of the cementation structure between the rocks can directly induce coalmine water-inrush accidents. To study the seepage stability of cemented and fractured coal rock under triaxial pressures, a self-designed triaxial seepage testing system was used and the permeability $k$ and non-Darcy factor $\beta$ of the cemented and fractured coal rock were tested. Furthermore, the 1D non-Darcy seepage equations were used to calculate the evolution criteria of the seepage loss stability. The results show the following: (1) The cemented structure in the KCP under the triaxial pressures can be easily destroyed. The damaged coal and rock body mainly exists in bulk form, and the permeability depends mainly on the effective stress of the particles. (2) The seepage process in the KCP structure is a combination of pore flow, fracture flow, and pipe flow, and the transition of the seepage state is closely related to the change in the magnitude of $\beta$. (3) Under the long-term effect of confined underground water, the migration of small fractured particles in the KCP will increase the structural porosity. If the parameter $\beta k^{2}$ reaches the threshold value, the seepage system will evolve into a pipeline flow state, eventually causing a water-inrush accident.
\end{abstract}

\section{Introduction}

The karst collapse pillar (KCP) is a common geological phenomenon in coal mining. It is a special geological structure formed by sedimentation and cementation of fractured coal rock $[1,2]$. KCPs commonly occur above a natural aquifer containing a large amount of groundwater [3] and the advancement of the working face in the mine causes the destruction of the bottom layer, which provides conditions for the formation of the KCP water channel. The instability of the seepage state can directly lead to waterinrush accidents [4-6] where groundwater inrush can cause severe damage to the coal mining operation. Therefore, the study of KCP permeability and its stability has attracted worldwide attention [7].

In recent years, research on KCP water inrush focused mainly on the formation cause, evolution mechanism, the KCP mechanical model, and seepage characteristics.
Extensive statistical data indicate that $\mathrm{KCP}$ water inrush is caused by karst sedimentation in the carbonate rock distribution area $[1,8,9]$, and the destruction of the limestone structure enables the formation of a channel for the inflow of high-pressure groundwater from the aquifer into the mine $[10,11]$. Furthermore, as the fractured rock undergoes dissolution and erosion, the resulting fine particles will migrate and disperse under the action of high-pressure water, and the pores and cracks in the rock around the KCP will be under mining conditions. As the inflow channel develops and expands, the seepage field and stress field inside and outside the karst collapse column change [12]. Zhu and Wei [13] established a fluid and damage-based model for simulating mining-induced water-inrush behavior considering the influence of a fault and a KCP. Bai et al. [3] established a plug model to describe the seepage flow characteristics of the coal seam floor containing a KCP. Yao et al. [14] established a fluid-solid coupling model of KCPs 
based on the seepage theory of porous media, using different methods to study water-inrush behavior. Xiang [15] conducted numerical experiments to simulate the groundwater influx of KCP. However, theoretical and experimental studies of KCP seepage characteristics are still lacking. Therefore, we carried out triaxial seepage tests to investigate the seepage state in KCPs, analyzed the seepage characteristics, and developed a new method for estimating seepage loss stability.

The evolution of the KPC instability water-inrush system is shown in Figure 1. When a KCP occurs, the fractured coalrock body will form a new cementation structure under the long-term dissolution and erosion of the water flow. Considering the gradation structure, the influence of cementation on the seepage stability is not negligible. Based on the above research, we used the Talbot theory to create cemented and fractured coal samples with different grading structures, and considering the influence of multilevel stress on the pore structure of coal, we used a triaxial permeameter to conduct steady-state tests of cemented fractured coal samples. The seepage test explores the effects of the cementation, gradation structure, and effective stress on the seepage stability of the fractured coal rock, and our analysis provides an important theoretical basis for the prediction and early warning of coalmine water-inrush accidents.

\section{Materials and Methods}

2.1. Sample Preparation. In order to study the seepage stability of the cemented structure between the fractured coal and rock, a series of cemented samples were prepared to test the seepage stability of the structure. The sample preparation process was as follows: First, to produce the specimens, fractured coal rock with different particle sizes was screened, and four particle sizes were selected for gradation. The particle sizes were $0-2.5 \mathrm{~mm}, 2.5-5.0 \mathrm{~mm}$, $5.0-7.5 \mathrm{~mm}$, and $7.5-10 \mathrm{~mm}$. According to the rock test requirements $[16,17], D$ of the sample to the maximum particle diameter $d$ should satisfy $D / d \geq 5$; therefore, the maximum particle size in the test was $10 \mathrm{~mm}$. Then, considering the long-term effect of KCP evolution, Wang et al. [18] carried out the experiment by preparing a weak cementation structure; according to the cement content requirements for the fracture testing of the fractured mudstone, the cementing material was selected as standard 425 cement, and the optimum amount of cement per specimen was selected as $50 \mathrm{~g}$. The selection of the particle size is based on the Talbot index theory [18] and the continuous grading theory [19], which defines the Talbot index $\mathrm{n}$ to range from $0-1$, so this test takes $n=0.1,0.2, \ldots, 1.0$ in order, corresponding to the sample number $\mathrm{M}-1$ and $\mathrm{M}-2$ to M-10. The coal particles were mixed with the cementing materials and an appropriate amount of water was added and the mixture stirred until evenly distributed. The ratio of the sample is shown in Table 1.

Finally, applying the initial pressure of $2 \mathrm{kN}$ and maintaining, each sample of $\varphi 50 \mathrm{~mm} \times 50 \mathrm{~mm}$ was prepared in the mold and stored in the mold in a cool place for 15 days and then dried in room air for 15 days, until the cement had completely solidified. The sample was then removed from the mold, sanded, and dried. A DDL600 rock mechanics test system was combined with a triaxial permeameter to carry out the seepage test on the cemented and fractured coal and coal rock. The triaxial seepage test system of the cemented coal rock is shown in Figure 2.

2.2. Test Equipment. From the perspective of rock mechanics, the KCP belongs to a special geological structure, which is mainly due to the dissolution of underground highpressure water. The fractured coal rock is dissolved in the long term and then cemented. The stability of the KCP depends on the integrity of the cemented structure. In order to further understand the seepage failure mechanism of the cemented structure in the KCP, a set of cemented coal-rock seepage test device was independently developed to carry out the triaxial seepage test on the cemented and fractured coal rock. The main structure of the device includes DDL600 electronic universal testing machine, three-axis percolation test cylinder, lateral pressure pump, and seepage pressure pump, with a computer, data acquisition device, voltage regulator, and so on. The three-axis seepage system of cemented coal rock is shown in Figure 3.

Considering the influence of the gradation structure on the seepage characteristics of the fractured coal-rock mass, the sample aggregate prepared in this paper includes four size ranges, and the distribution in the particle size range of each level obeys the Talbot theory $[14,20,21]$; namely,

$$
\frac{M_{d}}{M_{t}}=\left(\frac{d}{D}\right)^{n} \times 100 \% \text {, }
$$

where $M_{d}$ is the particle mass with particle size less than or equal to $D$ in the sample, $\mathrm{kg} ; M_{t}$ is the total mass of the fractured coal rock in the sample, $\mathrm{mm}$; $d$ is the particle size of the fractured coal rock, $\mathrm{mm}$; $D$ is the maximum particle size in the ratio, $\mathrm{mm}$; and $n$ is the Talbot index; the higher the value of $n$, the higher the content of large particles in the aggregate.

2.3. Test Methods. Structural coal-rock specimens of four different grades were subjected to seepage tests under gradual loading by applying five-stage loading $(1,5,10,20$, and $30 \mathrm{kN}$ ) in the axial direction. The specimens were tested at five levels of seepage pressure $(0.5,1.0,1.5,2.0$, and $2.5 \mathrm{MPa}$ ) under each axial load (Figure 4). The axial load $F$, the axial displacement $\Delta h$, and the loading time $t$ were recorded by the computer system. Then, the steady-state seepage method is used to carry out the test and record the data [22-24]. Previous research on the characteristics of cemented fractured rock showed that when the seepage time reached $3000 \mathrm{~s}$, the decrease in the permeability was about $73 \%-96 \%$ of the total reduction at $6000 \mathrm{~s}$, with the permeability decrease slowing in the later stages of penetration [19]. Therefore, in this test, to eliminate the test error caused by the creep effect of coal rock, the stress holding time at each stage was set at $3000 \mathrm{~s}$.

In order to ensure the reliability of the test data during the test, the percolation test under the same test conditions was 


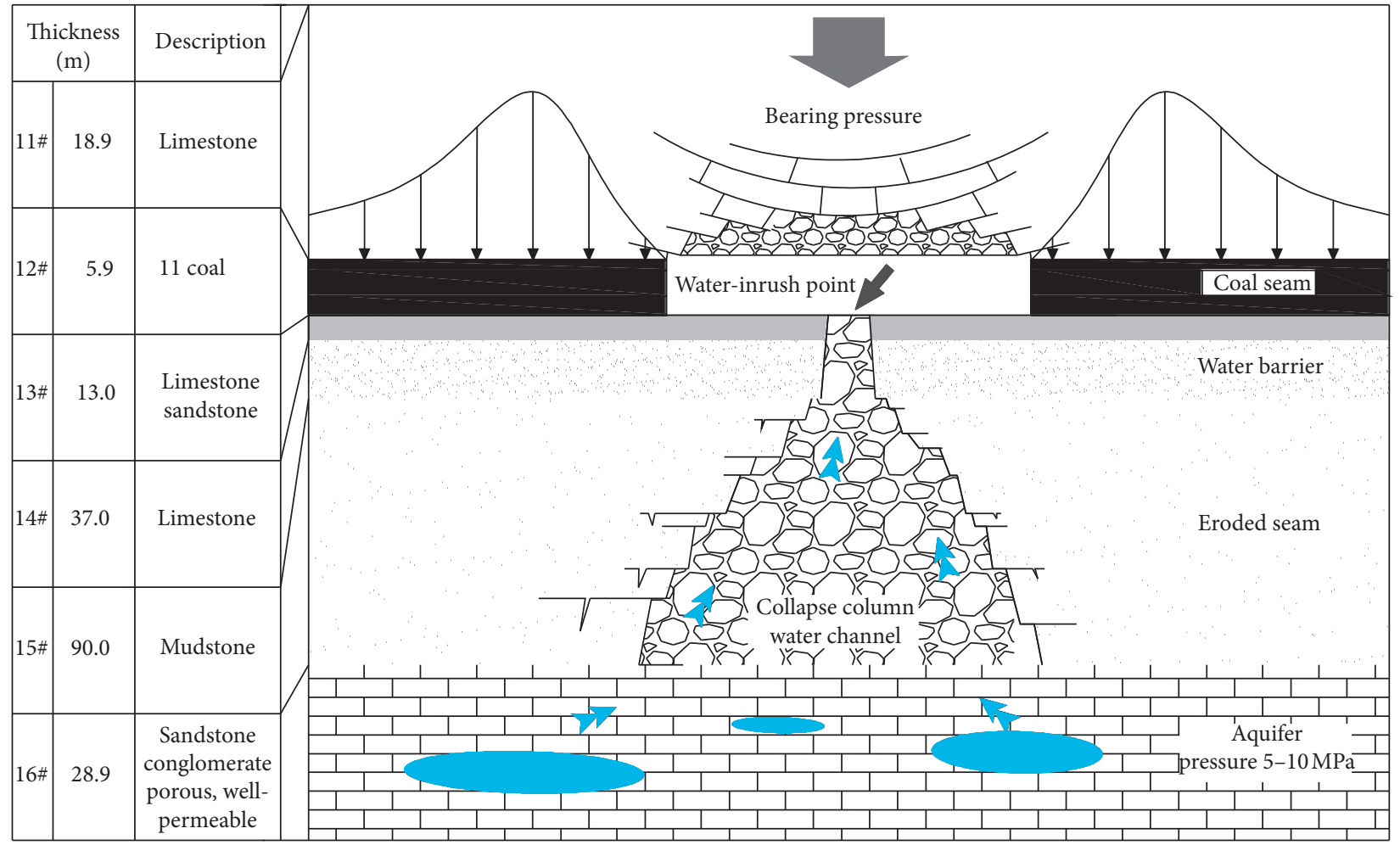

FIGURE 1: Illustration of KCP instability water-inrush system evolution.

TABle 1: The mass ratio of the sample.

\begin{tabular}{lcccccccccc}
\hline \multirow{2}{*}{ Particle sizes $(\mathrm{mm})$} & \multicolumn{1}{c}{ Talbot index $n$} \\
& 0.1 & 0.2 & 0.3 & 0.4 & 0.5 & 0.6 & 0.7 & 0.8 & 0.9 & 1.0 \\
\hline $0 \sim 2.5$ & 87.1 & 75.8 & 66.0 & 57.4 & 50.0 & 43.5 & 37.9 & 33.0 & 28.7 \\
$2.5 \sim 5$ & 6.2 & 11.3 & 15.3 & 18.4 & 20.7 & 22.5 & 23.7 & 24.4 & 24.9 & 25.0 \\
$5 \sim 7.5$ & 3.9 & 7.4 & 10.5 & 13.3 & 15.9 & 18.2 & 20.2 & 20.0 & 23.6 & 25.0 \\
$7.5 \sim 10$ & 2.8 & 5.5 & 8.2 & 10.9 & 13.4 & 15.8 & 18.2 & 22.6 & 22.8 & 25.0 \\
\hline
\end{tabular}

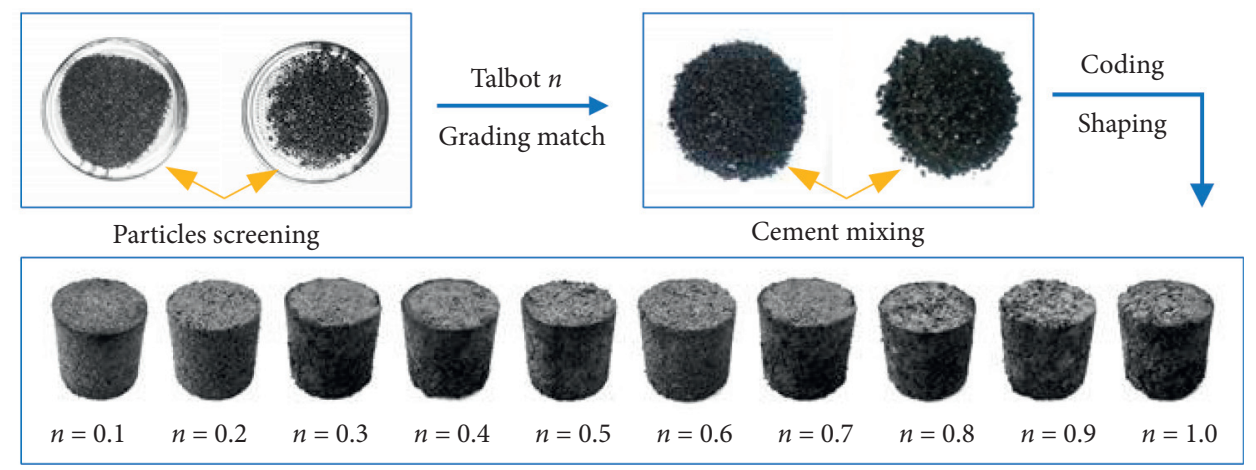

Figure 2: Cemented samples made at different values of $n$.

repeated 3 times, and the average value was taken as the final test result. The specific test procedures mainly include (1) assembling the coal-rock three-axis seepage test system and measuring the initial height $h_{0}$ of the sample; (2) starting the press, setting the initial pressure to $0.2 \mathrm{kN}$, and recording the initial displacement of the test machine as zero; (3) starting lateral pressure pump, injecting liquid saturation, loading axial pressure $10 \mathrm{kN}$, and maintaining; (4) keeping the lateral pressure constant, opening the seepage pressure pump, and starting the seepage test; (5) changing the lateral pressure 

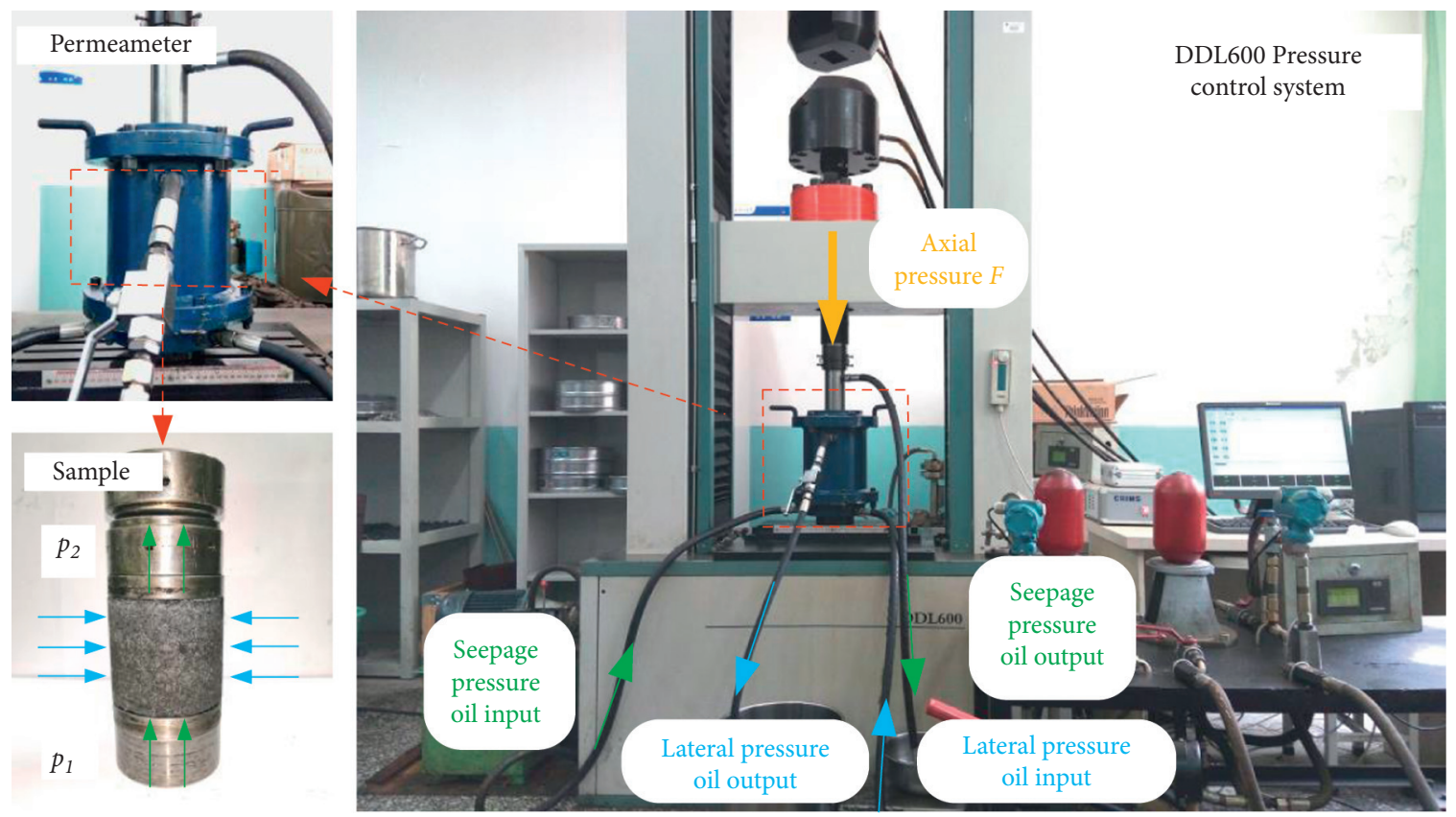

FIgURE 3: Triaxial seepage test system for cemented fractured coal rock.

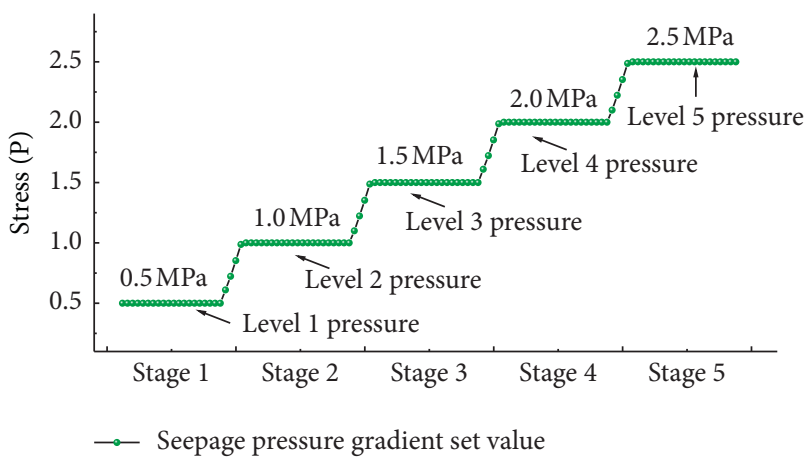

Figure 4: Schematic diagram of seepage pressure loading.

through the hydraulic pump overflow valve, completing different seepage pressure tests, and recording data; (6) changing the value of lateral pressure, completing pressure tests of different lateral pressures, and recording data; (7) pressure relief, unloading, and end of the test.

In the triaxial seepage test, the schematic diagram of loading at each stage is shown in Figure 5. It includes (1) applying axial load, that is, providing axial stress $\sigma_{1}$ by loading of the press; (2) applying lateral pressure; that is, the circumferential pressure $\sigma_{2}=\sigma_{3}$ is provided by the hydraulic pump; (3) the seepage pressure applied; that is, the seepage pressure $p$ of the stable pressure is supplied through another hydraulic oil pump. Subsequently, the line pressure is adjusted by opening the overflow valve to complete the penetration test under different axial pressures, different lateral pressures, and different seepage pressures.

\section{Results and Discussion}

3.1. Basic Parameter Test. Each group of coal samples with different cracks is set to 5 levels of lateral pressure, and each stage of lateral pressure is set to 4 levels of seepage pressure. The lateral pressure is selected from the range of $0.5-2.0 \mathrm{MPa}$. In the test, it is usually ensured that the lateral pressure is $0.2-0.5 \mathrm{MPa}$ larger than the pore pressure [25-27]. If the pore pressure is higher than the lateral pressure, the plastic insulating tape and the heat-shrinkable plastic sleeve will be fractured. Therefore, the pressure of the lateral pressure during the test was set to a total of five grades of 3.0-5.0 MPa, and the seepage flow at each stage of the test was recorded. Through analysis, the results of the percolation parameters are shown in Table 2.

3.2. Seepage Parameter Analysis. Effective stress is the fundamental factor leading to particle deformation of fractured coal rock. The principle is to simplify the macroscopic threedimensional force of coal rock, which is equivalent to the effective stress of coal-rock matrix, so as to simplify the complex stress conditions. Therefore, the effective stress can better reflect the stress of the cemented and fractured coal rock under the triaxial stress. The effective stress reflects the stress of the cemented fractured coal rock under triaxial stress. According to the effective stress principle of Terzaghi [28, 29], the effective stress can be written as

$$
\left.\begin{array}{l}
\vec{\sigma}_{x x}^{\prime}=\vec{\sigma}_{x x}-p \\
\vec{\sigma}_{y y}^{\prime}=\vec{\sigma}_{y y}-p \\
\vec{\sigma}_{z z}^{\prime}=\vec{\sigma}_{z z}-p
\end{array}\right\},
$$

where $\vec{\sigma}_{x x}^{\prime}=\vec{\sigma}_{y y}$ is the hoop stress, equal to the confining pressure $\sigma_{3}$ applied in the test, $\vec{\sigma}_{z z}$ is the axial stress, equal to $\sigma_{1}$ loaded by the test machine, $p_{1}$ is the inlet pressure, $p_{2}$ is the outlet pressure (approximately 0 here), the average fracture pressure is $p=\left(p_{1}+p_{2}\right) / 2$, and $\delta$ is the Kronecker delta. One has 


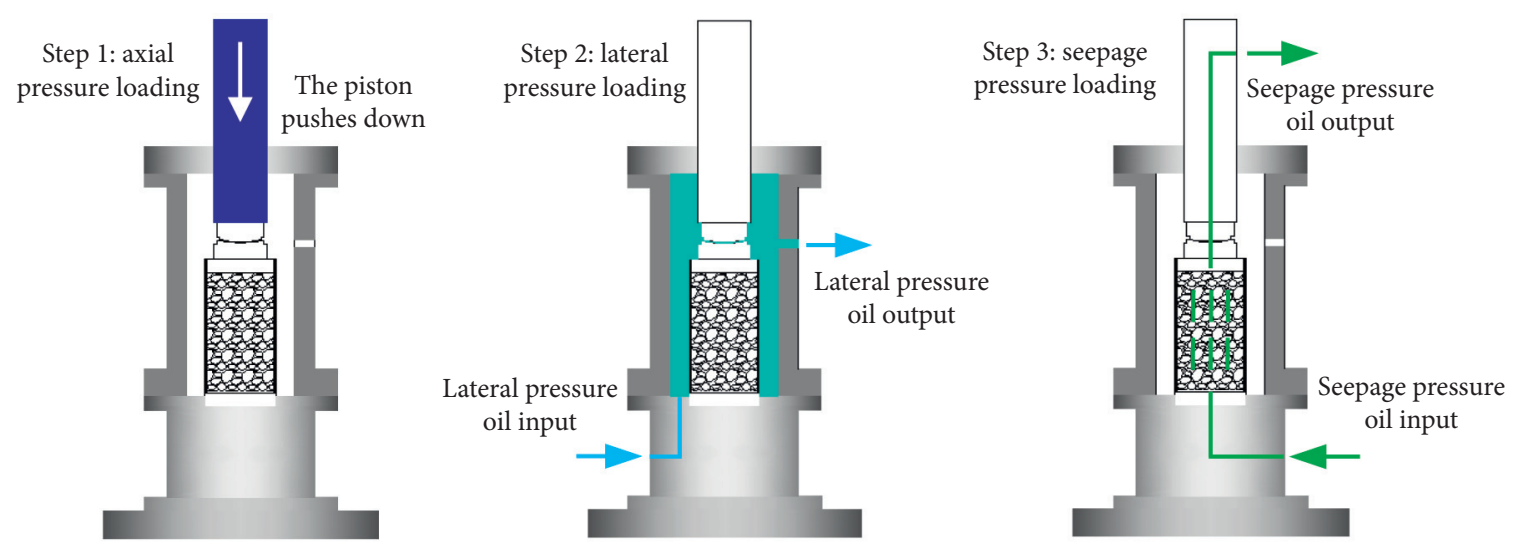

Figure 5: Schematic diagram of different stages of triaxial seepage.

TABLE 2: Coal sample test parameters.

\begin{tabular}{lcccccccccc}
\hline Sample & M-1 & M-2 & M-3 & M-4 & M-5 & M-6 & M-7 & M-8 & M-9 & M-10 \\
\hline Talbot $n$ & 0.1 & 0.2 & 0.3 & 0.4 & 0.5 & 0.6 & 0.7 & 0.8 & 0.9 & 1.0 \\
$h_{0}(\mathrm{~mm})$ & 51.2 & 49.3 & 51.8 & 49.8 & 52.0 & 52.1 & 51.9 & 51.2 & 50.9 & 50.3 \\
$\begin{array}{l}\sigma_{\mathrm{b}} \\
(\mathrm{MPa})\end{array}$ & 2.043 & 1.086 & 1.042 & 1.069 & 2.951 & 3.113 & 3.447 & 2.694 & 3.662 & 2.017 \\
$\begin{array}{l}\text { Critical } \\
\text { value }\end{array}$ & -15.0 & -14.9 & -13.1 & -13.4 & -15.1 & -15.3 & -14.1 & -13.2 & -13.8 & -15.4 \\
\hline
\end{tabular}

$h_{0}$ represents the initial height of the sample and $\sigma_{\mathrm{b}}$ represents the uniaxial peak compressive strength of the sample.

$$
\delta_{i j}= \begin{cases}1, & i=j, \\ 0, & i \neq j .\end{cases}
$$

The effective stress in the test is described by the mean effective stress:

$$
\vec{\sigma}_{e}=\frac{\left(\vec{\sigma}_{x x}^{\prime}+\vec{\sigma}_{y y}^{\prime}+\vec{\sigma}_{z z}^{\prime}\right)}{3},
$$

When $p_{2}=0$, the average effective stress under the triaxial stress condition of the fractured sample is

$$
\vec{\sigma}_{e}=\frac{1}{3}\left(2 \vec{\sigma}_{x x}+\vec{\sigma}_{z z}\right)-\frac{1}{2}\left(p_{1}+p_{2}\right)=\frac{1}{3}\left(2 \sigma_{3}+\sigma_{1}\right)-\frac{1}{2} p_{1},
$$

where $\sigma_{3}$ is the test lateral pressure, in $\mathrm{MPa}$, and $\sigma_{1}$ is the axial stress, in $\mathrm{MPa}$.

The relationship between effective stress and permeability is shown in Figure 6. For all the tested grading structures, the permeability of the coal decreased with increasing effective stress as the permeate seeped into the cemented coal. A negative exponential curve can be fitted to the permeability results corresponding to the following regression equation:

$$
k=a e^{b \sigma_{c}}
$$

where $k$ represents the permeability, in $\mathrm{kg} / \mathrm{m}^{3}$, and $\sigma_{\mathrm{c}}$ is the effective stress, in MPa. The curve correlation coefficient $R^{2}$ is greater than 0.9 .

The results can be explained as follows: when the lateral pressure is constant, the permeability of the fractured coal rock will decrease with increasing axial pressure. At this stage, $\sigma_{\mathrm{c}}=0.26-2.05 \mathrm{MPa}$ and the cemented fractured rock is quickly compacted and enters the fast compaction stage. The maximum decrease of $k$ occurs when $n=0.9$. When the axial pressure is further increased, $\sigma_{c}>2.05 \mathrm{MPa}$, and the decrease of $k$ with increasing axial pressure is less sharp because the cementation between the particles is substantially destroyed, the particles of the coal rock are fractured, and fine particles are generated. With the migration, the pressure-bearing skeleton structure changes and enters the skeleton readjustment stage.

3.3. Non-Darcy Effect Analysis. For porous media, pore channels refer to microchannels that penetrate each other in porous media and are also the main parameters for fluid transport properties of porous media [30]. The void ratio is related to the porous medium skeleton structure and is also susceptible to external loads. For the pore structure of cemented and fractured coal rock, the change of porosity is an indispensable part of studying the permeability characteristics. The porosity $\varphi$ of the specimen at any stage of the test can be calculated as

$$
\phi=1-\frac{m}{\rho_{1} A(h-\Delta h)},
$$

where $m$ is the quality of the cemented fractured sample, in $\mathrm{kg} ; h$ is the initial height of the rock sample, in $m ; \rho_{1}$ is the density of the fractured coal particles, in $\mathrm{kg} / \mathrm{m}^{3} ; \Delta h$ is the axial displacement, in $m$; and $A$ is the cross-sectional area of the sample, in $\mathrm{m}^{2}$.

When liquid seeps through the rock sample, $p_{1}$ and $p_{2}$ are the pore pressures of the inlet and outlet ends of the seepage with respect to the atmosphere. $p_{2}$ is the outlet 


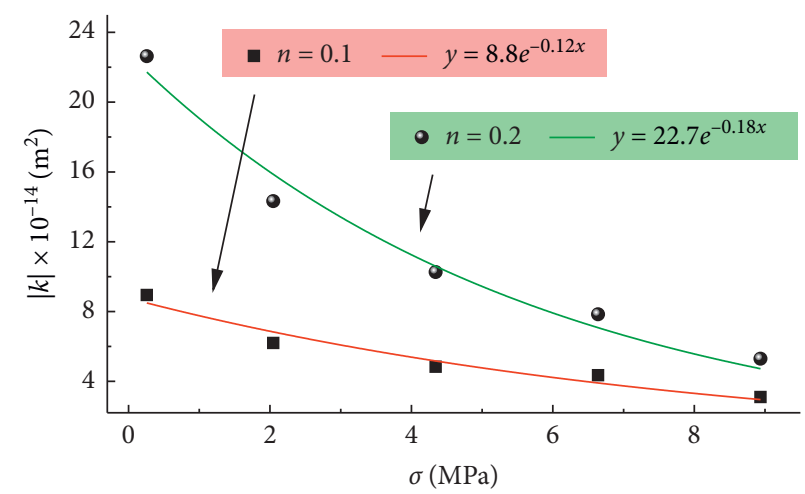

(a)

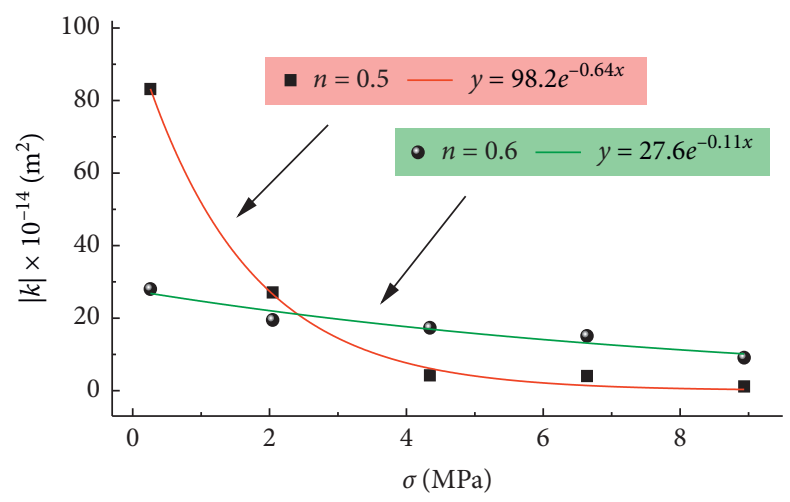

(c)

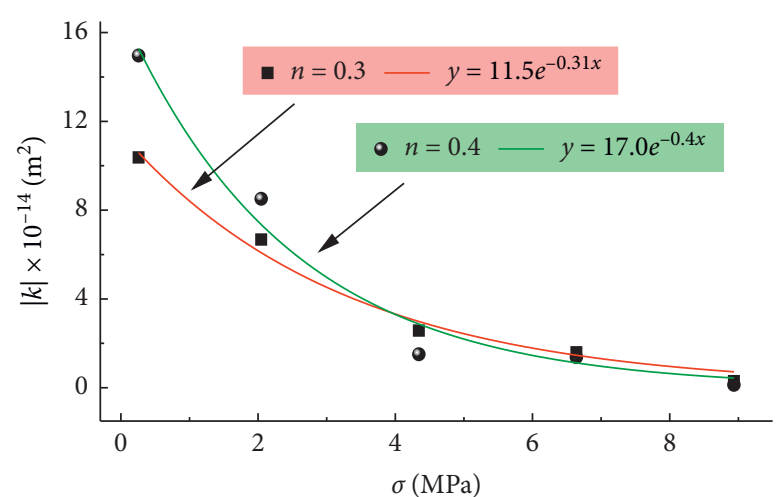

(b)

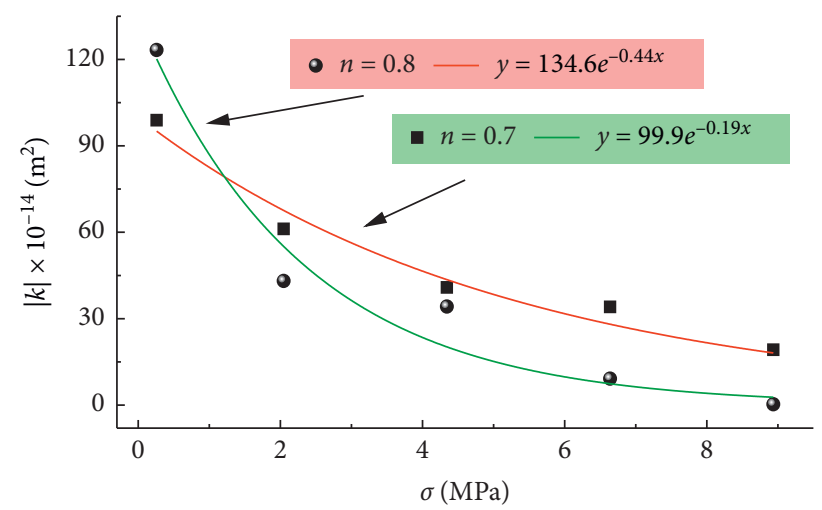

(d)

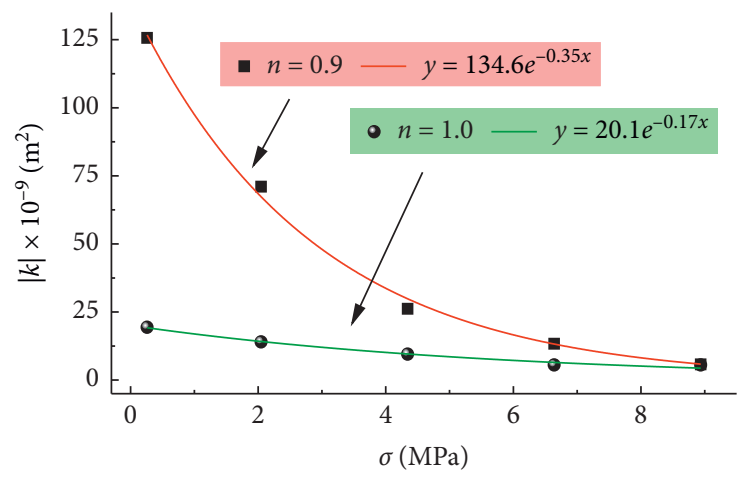

(e)

FiguRE 6: Relationship between effective stress and permeability of samples. (a) $n=0.1 ; n=0.2$. (b) $n=0.3 ; n=0.4$. (c) $n=0.5$; $n=0.6$. (d). $n=0.7 ; n=0.8$. (e) $n=0.9 ; n=1.0$.

pressure(approximate 0 here), and the pressure gradient after each stage of compression is

$$
\frac{\partial p}{\partial x}=\frac{p_{2}-p_{1}}{H}=-\frac{p_{1}}{H}
$$

$H=(h-\Delta h)$ is the height of the compressed rock sample, in $m$. The theoretical and experimental studies on the non-Darcy seepage characteristics of a fractured coal body are based on the Forchheimer empirical formula $J=$ $a v+b v^{2}$ [31-33], which takes into account the inertia and turbulence effects of the permeate and is a method that accurately reflects the non-Darcy seepage state; the following relationship is satisfied between the pressure gradient $\partial p / \partial x$ and the percolation velocity $v$ :

$$
-\frac{\partial p}{\partial x}=\frac{\mu}{k} v+\rho \beta v^{2}
$$

where $\partial p / \partial x$ is the pressure gradient across the sample; $\mu$ is the dynamic viscosity of water, in Pa.s; $k$ is the permeability of broken rock under a certain pressure, in $\mathrm{m}^{2} ; v$ is the percolation velocity, in $\mathrm{m} / \mathrm{s} ; \rho$ is the density of water, in $\mathrm{kg} /$ $\mathrm{m}^{3}$; and $\beta$ is a non-Darcy factor, indicating the degree of deviation from the linear law, in $\mathrm{m}^{-1}$. When $\beta=0$, the seepage obeys Darcy's law.

The distribution of $\beta$ in non-Darcy flow in the tested specimens is shown in Figure 7. The data show that $\beta$ may be either positive or negative. In the initial stage of the test, the axial pressure and seepage pressure were small and the porosity was 


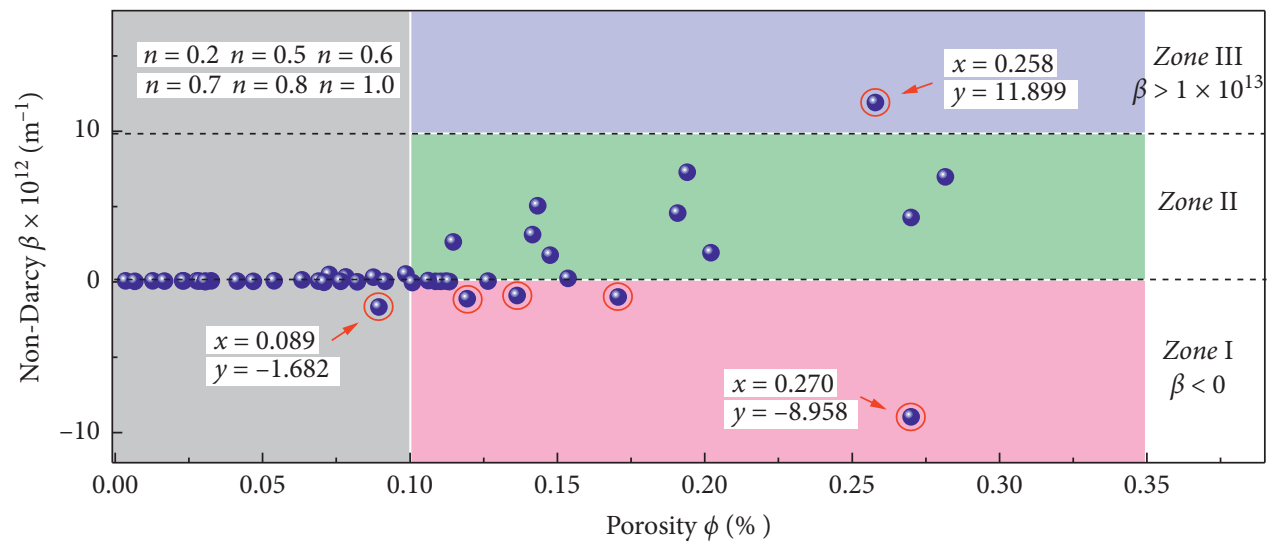

Figure 7: Distribution of $\beta$-factors in non-Darcy flow in the tested specimens.

large; $\beta$ is positive and appears in zone II (the stable zone). As the pressure on the sample increases, the deformation and fracturing of the skeleton particles lead to a decrease in permeability. When $k \leq 10^{-12} \mathrm{~m}^{2}, \beta$ is most likely to have a negative value and to appear in region I (the instability zone); when $\beta \geq 10^{13} \mathrm{~m}^{-1}$, it is also likely to become negative and shift to zone III (the easy mutation zone). In both conditions, the fractured rock sample will have a stable seepage loss. For $n=0.3,0.4$ or 0.5 , the $\beta$ distribution of the skeleton structure is the most dispersed, the stability of the seepage state is poor, and the deviation from the stable zone is the most obvious, indicating that seepage loss is most likely to occur.

3.4. Estimate of Seepage Loss Stability. A large number of experiments have shown that water-inrush or coal and gas outburst accidents caused by seepage loss in mining projects are often caused by sudden changes in the seepage parameters. Therefore, a dynamic method should be used to study the non-Darcy seepage differential dynamic system of fractured coal rock [34-36]. For one-dimensional (1D) passive flow, the 1D non-Darcy seepage dynamics equations of fractured coal rock can be expressed as

$$
\left\{\begin{array}{l}
\rho_{0} \phi_{0} c_{t} \frac{\partial p}{\partial t}+\frac{\partial(\rho v)}{\partial x}=0 \\
\rho c_{a} \frac{\partial v}{\partial t}=-\frac{\partial p}{\partial x}-\frac{\mu}{k} v+\rho \beta v^{2}+F
\end{array}\right.
$$

For an incompressible fluid and ignoring the acceleration $\rho c_{a} \partial v / \partial x$ and the volume force $F,(10)$ can be simplified as

$$
\left\{\begin{array}{l}
\frac{\partial p}{\partial t}=-\frac{1}{\phi_{0} c_{t}} \frac{\partial v}{\partial x} \\
\frac{\partial p}{\partial x}=-\frac{\mu}{k} v+\rho \beta v^{2} .
\end{array}\right.
$$

The first and second formulas of (11) are separately biased to $x$ and $t$ and then added to obtain

$$
\left(-\frac{\mu}{k}+2 \rho \beta v\right) \frac{\partial v}{\partial t}+\frac{1}{\phi_{0} c_{t}} \frac{\partial^{2} v}{\partial x^{2}}=0 .
$$

We define the variable $Z$ as

$$
Z=\left(-\frac{\mu}{k}+2 \rho \beta v\right) \cdot \phi_{0} c_{t} .
$$

Then, (12) can be simplified as

$$
Z \frac{\partial Z}{\partial t}+\frac{\partial^{2} Z}{\partial x^{2}}=0
$$

Among them, the traveling wave method is an important way to solve this kind of nonlinear wave equation. Zakharov equation [37] and the analytical solution of the KadomtsevPetviashvili equation [38] (such as the solitary wave solution) are obtained by this method. So, we can set

$$
Z=f(\xi)=f(x-c t) .
$$

Substituting (15) into (14),

$$
-c f f^{\prime}+f^{\prime \prime}=0 .
$$

The stability criterion is then

$$
-\frac{1}{2} c f^{2}(\xi)+f^{\prime}(\xi)=C_{1} .
$$

When $C_{1}=-c f^{2}(0)+f^{\prime}(0)=0$, the solution to (17) is

$$
f(\xi)=-\frac{c}{2\left(\xi-\xi_{0}\right)} \text {. }
$$

When $C_{1}=-c f^{2}(0)+f^{\prime}(0)>0$, the solution to (17) is

$$
f(\xi)=\sqrt{\frac{2 C_{1}}{c}} \operatorname{tg}\left[\sqrt{\frac{C_{1} c}{2}}\left(\xi-\xi_{0}\right)\right] .
$$

When $C_{1}=-c f^{2}(0)+f^{\prime}(0)<0$, the solution to (17) is

$$
f(\xi)=\sqrt{\frac{2\left|C_{1}\right|}{2}} \operatorname{th}\left[\sqrt{\frac{\left|C_{1}\right| c}{2}\left(\xi-\xi_{0}\right)}\right] .
$$



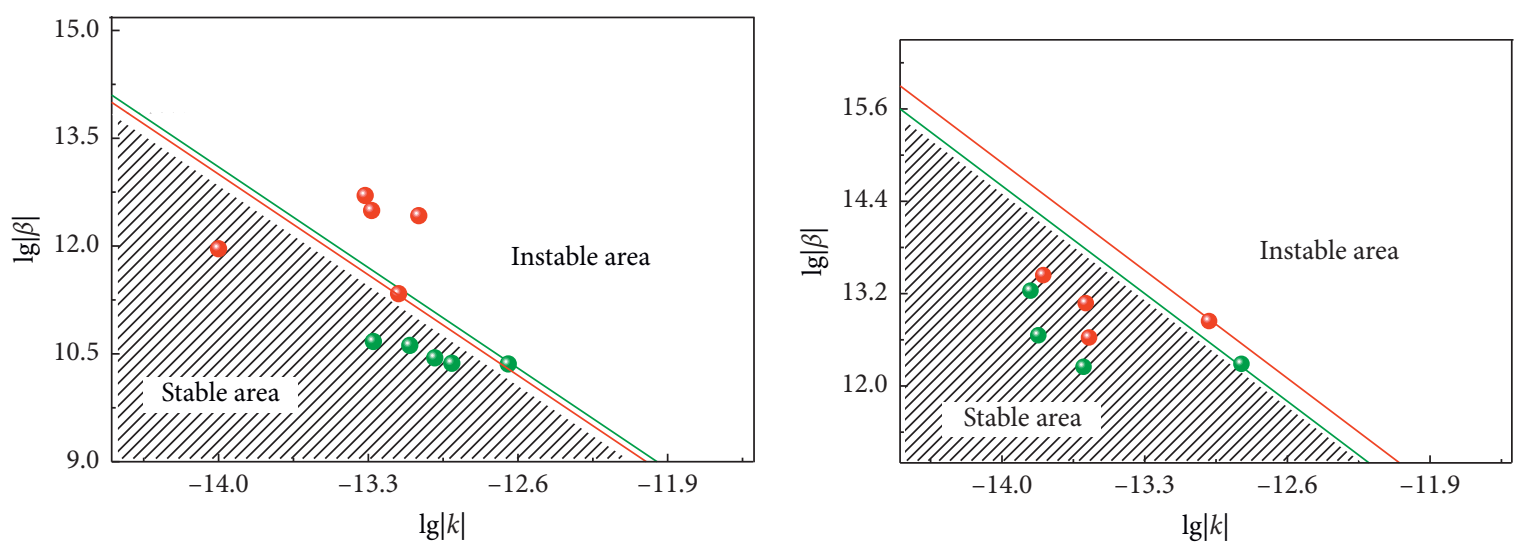

$\begin{aligned} n & =0.1 \lg \beta+2 \lg k<-15.0 \\ n & =0.2 \lg \beta+2 \lg k<-14.9\end{aligned}$

(a)

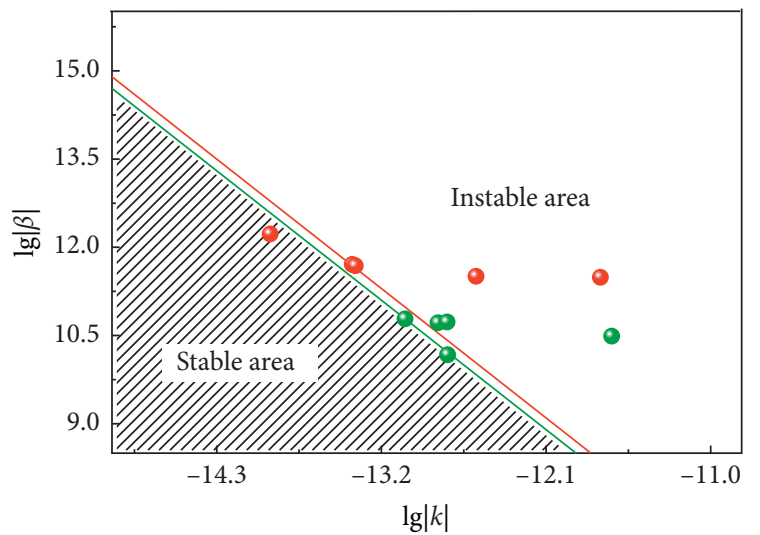

$-n=0.3 \lg \beta+2 \lg k<-13.1$

$-n=0.4 \lg \beta+2 \lg k<-13.4$

(b)

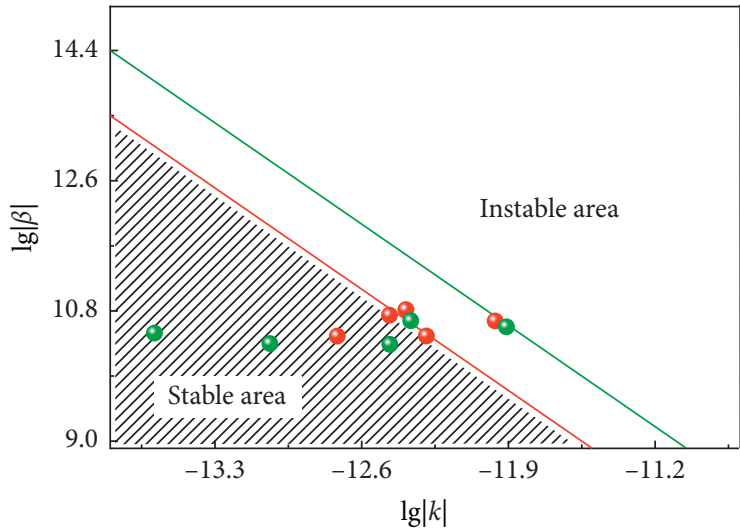

$\begin{aligned} n & =0.5 \lg \beta+2 \lg k<-15.1 \\ n & =0.6 \lg \beta+2 \lg k<-15.3\end{aligned}$

$-n=0.5 \lg \beta+2 \lg k<-14.1$

$n=0.6 \lg \beta+2 \lg k<-13.2$

(c)

(d)

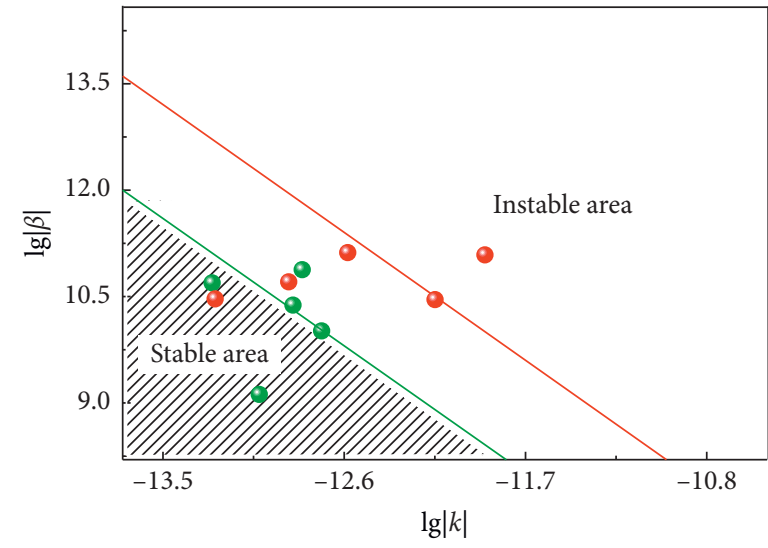

$-n=0.9 \lg \beta+2 \lg k<-13.8$

- $n=1.0 \lg \beta+2 \lg k<-15.4$

(e)

FIGURE 8: The seepage states of stability of fractured coal. (a) $n=0.1 ; n=0.2$. (b) $n=0.3 ; n=0.4$. (c) $n=0.5 ; n=0.6$. (d) $n=0.7 ; n=0.8$. (e) $n=0.9 ; n=1.0$. 
TABLE 3: Symbol comment list.

\begin{tabular}{lccc}
\hline Symbol & Physical meaning and interpretation & Symbol & Physical meaning and interpretation \\
\hline$\rho, \rho_{0}$ & Density and initial density, $\mathrm{kg} / \mathrm{m}^{3}$ & $Z$ & New functions defined, $Z=f(\xi)$ \\
$\phi, \phi_{0}$ & Porosity and initial porosity, $\%$ & $f, f^{\prime}, f^{\prime \prime}$ & Representation function and its various derivatives \\
$c_{\mathrm{t}}$ & Comprehensive compression factor & $\xi, \xi_{0}$ & New variables defined, $\xi=x-c t$ \\
$c_{a}$ & Acceleration coefficient & $k, k_{0}$ & Permeability and initial permeability, $\mathrm{m}^{2}$ \\
$p$ & Seepage pressure, $\mathrm{MPa}$ & $\beta, \beta_{0}$ & Non-Darcy factor and initial factor, ${ }^{-1}$ \\
$t$ & Time, $\mathrm{s}$ & $F$ & Facial strength, $N$ \\
$v$ & Seepage velocity, $\mathrm{m} / \mathrm{s}$ & $C_{1}$ & Integral constant \\
$x$ & Seepage displacement, $\mathrm{m}$ & $c$ & Constant \\
$\mu$ & Dynamic viscosity, Pa.s & $H$ & Height, $\mathrm{m}$ \\
\hline
\end{tabular}

So, the dynamics of the system depend on the initial conditions; the stability conditions of the non-Darcy seepage differential dynamic system are as follows:

If $C_{1}=-c f^{2}(0)+f^{\prime}(0)<0$, the system has two flat steady states $f_{1}=\sqrt{-2 C_{1} / c}$ and $f_{2}=-\sqrt{-2 C_{1} / c}$, and the equilibrium state is stable.

If $C_{1}=-c f^{2}(0)+f^{\prime}(0) \geq 0$, the system is unstable and it is impossible to reach a steady state regardless of the conditions of the percolation system. The meaning of the formula involved in the above-mentioned formula derivation is shown in Table 3.

In this test, the skeleton structure is cemented and fractured coal rock, and seepage stability was tested under triaxial pressure. The boundary conditions of the equation are $\left.(\partial p / \partial t)\right|_{t=0}=0 ;\left.(\partial v / \partial x)\right|_{t=0}=0$, and the initial moment velocity distribution can be solved:

$$
v(0, x)=\frac{(\mu / k) \sqrt{(\mu / k)^{2} 4 \rho \beta\left(p_{1} / H\right)}}{2 \rho \beta} .
$$

Then, $Z(0, x)=-\sqrt{(\mu / k)^{2} 4 \rho \beta\left(p_{1} / H\right)}, Z^{\prime}(0, x)=0$, and the conditions for instability are

$$
C_{1}=-c f^{2}(0)+f^{\prime}(0)=-c Z^{2}(0,0) \geq 0 .
$$

Thus, the system instability conditions with the permeability, hydrodynamics, and pressure boundary conditions are obtained:

$$
\left(\frac{\mu}{k}\right)^{2}-4 \rho \beta \frac{(\Delta p)_{t=0}}{H}<0 .
$$

Here, $\mu$ is the kinematic viscosity of the permeate, in Pa.s; $\rho$ is the permeate density, in $\mathrm{kg} / \mathrm{m}^{3} ; \Delta p$ is the pressure difference across the sample, in MPa; and $H$ is the height of the coal sample, in $m$.

DTE22 hydraulic oil was used as the permeate in the tests, with a density of $\rho=874 \mathrm{~kg} / \mathrm{m}^{3}$ and dynamic viscosity $\mu=1.96 \times 10^{-2} \mathrm{~Pa} \cdot \mathrm{s}$. Taking the first set of samples as an example, $H=51.2 \mathrm{~mm}$, the permeability $k_{0}$ obtained by the test is $7.5 \times 10^{-11}, \beta_{0}=2.17 \times 10^{11}$, and $\triangle p=0.5 \times 10^{6} \mathrm{~Pa}$. The threshold of instability is then

$$
\beta_{0} k_{0}^{2}=1.05 \times 10^{-15} \text {. }
$$

Taking the logarithm on both sides of (24) yields the critical curve expression:

$$
\lg \beta+2 \lg k<-15.0 \text {. }
$$

Similarly, using the above calculation method, the threshold value of the seepage loss for $n=0.1,0.2, \ldots, 1.0$ can be calculated. With $\lg \beta$ and $\lg k$ being the coordinate axes, a straight line can be drawn on the direct coordinate system. This line is the dividing line between the stable zone and the unstable zone. The seepage states of the fractured coal body under different gradation structures are shown in Figure 8.

For the stability analysis in Figure 8, the specimens were subjected to triaxial stress, axial pressure of $1-30 \mathrm{kN}$ was applied to the fractured cemented coal specimens, and the seepage pressure was adjusted within $0.5-2.5 \mathrm{MPa}$. It was estimated that seepage occurred through $24 \%$ of the sample. There were some stages of instability. To ensure the stability of the seepage flow through the fractured coal-rock body, the seepage pressure and lateral pressure need to be maintained within certain ranges to satisfy the relationship:

$$
\lg \beta+2 \lg k<L,
$$

where $L=\min \left\{L_{0.1} L_{0.2} \cdots L_{1.0}\right\}$, when $n=0.1,0.2, \ldots, 1.0$, and $\mathrm{Li}$ is the sample that reached the critical value of the instability at the initial state.

The instability curve of the test is

$$
\lg \beta+2 \lg k<-15.4 \text {. }
$$

At this point, the threshold of instability is $\beta k^{2}=3.90 \times 10^{-16} \mathrm{~m}^{3}$.

The analysis results can be explained as follows: (1) In cemented fractured coal rock with different grading structures, when there is a high content of small particles or the rock is finely fractured, blockage of the seepage channel is likely to cause the seepage state to change. (2) Under external loading, the pressure increases and damage to the skeletal structure can lead to the collapse of the pore channels, resulting in a sudden change in gas permeability, which ultimately leads to a stable runoff.

\section{Conclusions}

To study the evolution mechanism of KCP-induced mine water-inrush events, a triaxial seepage test of fractured coal rock with different grading structures was carried out. The important factors affecting the permeability of fractured coal rock were obtained, and the formulation for estimating the seepage flow was developed. Two criteria were found for 
instability assessment. The following conclusions were drawn:

(1) The effective stress is a key factor in determining the permeability of fractured coal rock. The permeability of coal with different grades of rock will decrease exponentially as the effective stress increases. When the effective stress is less than $2.05 \mathrm{MPa}$, the skeleton structure of the coal rock is in the rapid compaction stage which increases the pressure in the skeleton structure; then, the skeleton pressure damage enters the structural readjustment stage.

(2) The change in the order of magnitude of the nonDarcy flow factor $\beta$ is the first criterion for estimating whether the seepage loss is stable. Thus, in the process of particle compaction in the skeleton structure, if the permeability $k$ decreases by an order of 10 or the magnitude of $\beta$ increases to 6 or more, the percolation system will lose its stability.

(3) The value of the seepage parameter $\beta k^{2}$ of the fractured coal body is the second criterion for judging the stability of the system. Based on our analysis of the mechanism of seepage loss of fractured coal rock, steady flow occurs when $\beta k^{2}$ is less than the critical value of $3.9 \times 10^{-16}$ under the initial pressure gradient.

\section{Data Availability}

The data used to support the findings of this study have not been made available because of confidentiality reasons.

\section{Conflicts of Interest}

The authors declare that there are no conflicts of interest regarding the publication of this paper.

\section{Acknowledgments}

This work was supported by the National Natural Science Foundation of China under Grant nos. 51774234 (Study on the Mechanism of Water-Gas Coupling Fracture Expansion and Ultrasonic Characteristics of Coal Rock in Drilling Holes), 51874234 (Study on Mechanism and Parameter Optimization of Carbon Dioxide Deep Hole Pre-Cracking Blasting), and 51604214.

\section{References}

[1] H. Keqiang, Y. Guangming, and L. Yaoru, "Palaeo-karst collapse pillars in northern China and their damage to the geological environments," Environmental Geology, vol. 58, no. 5, pp. 1029-1040, 2009.

[2] D. Ma, H. Duan, X. Li, Z. Li, Z. Zhou, and T. Li, "Effects of seepage-induced erosion on nonlinear hydraulic properties of broken red sandstones," Tunnelling and Underground Space Technology, vol. 91, Article ID 102993, 2019.

[3] H. Bai, D. Ma, and Z. Chen, "Mechanical behavior of groundwater seepage in karst collapse pillars," Engineering Geology, vol. 164, pp. 101-106, 2013.
[4] J. Wu, M. Feng, B. Yu, W. Zhang, X. Ni, and G. Han, "Experimental investigation on dilatancy behavior of water-saturated sandstone," International Journal of Mining Science and Technology, vol. 28, no. 2, pp. 323-329, 2018.

[5] P. Bukowski, "Water hazard assessment in active shafts in upper silesian coal basin mines," Mine Water Environment, vol. 30, no. 4, pp. 302-311, 2010.

[6] C. Ping, W. Hua, J. Jin et al., "Experimental study of the fracture failure of sandstone containing hole and fissure under seepage water pressure," China University of Mining and Technology, vol. 47, pp. 240-246, 2008.

[7] K. He, S. Zhang, F. Wang, and W. Du, "The karst collapses induced by environmental changes of the groundwater and their distribution rules in north China," Environmental Earth Sciences, vol. 61, no. 5, pp. 1075-1084, 2010.

[8] X. Fang and Y. Fu, "Impact of coal mining on karst water system in north China," Procedia Earth \& Planetary Science, vol. 3, pp. 293-302, 2011.

[9] H. Keqiang, G. Dong, D. Wen, and W. Ronglu, "The effects of karst collapse on the environments in north China," Environmental Geology, vol. 52, no. 3, pp. 449-455, 2007.

[10] D. Ma, J. Wang, and Z. Li, "Effect of particle erosion on mining-induced water inrush hazard of karst collapse pillar," Environmental Science and Pollution Research, vol. 26, no. 19, pp. 19719-19728, 2019.

[11] F. Jinyan, L. Xuhang, and Y. Zhiquan, "Numerical simulation study on the mining-induced fracture evolution of steep coal seam," Journal of China Coal Society, vol. 42, no. 8, pp. 1971-1978, 2017.

[12] H. Kong and L. Wang, "Seepage problems on fractured rock accompanying with mass loss during excavation in coal mines with karst collapse columns," Arabian Journal of Geosciences, vol. 11, no. 19, 2018.

[13] W. C. Zhu and C. H. Wei, "Numerical simulation on mininginduced water inrushes related to geologic structures using a damage-based hydromechanical model," Environmental Earth Sciences, vol. 62, no. 1, pp. 43-54, 2011.

[14] B. H. Yao, H. B. Bai, J. P. Wei, and D. Ma, "Numerical study on seepage property of karst collapse pillars under particle migration," Computer Modeling in Engineering and Sciences, vol. 91, no. 2, pp. 81-100, 2013.

[15] Y. Xiang, "The mechanics model on flooding process of collapse pillar," Coal Geology Exploration, vol. 21, no. 5, pp. 36-39, 1993.

[16] H. Li, "Research on seepage properties and pore structure of the roof and floor strata in confined water-rich coal seams: taking the xiaojihan coal mine as an example," Advances in Civil Engineering, vol. 2018, pp. 1-8, 2018.

[17] T. Zhang, L. Zhang, S. Li, J.-L. Liu, H.-Y. Pan, and X. Ji, "Wave velocity and power spectral density of hole-containing specimens with different moisture content under uniaxial compression," Energies, vol. 11, no. 11, p. 3166, 2018.

[18] G. Wang, P. Wang, Y. Guo, and W. Li, "A novel true triaxial apparatus for testing shear seepage in gas-solid coupling coal," Geofluids, vol. 2018, Article ID 2608435, pp. 1-9, 2018.

[19] B. Yu, Z. Chen, Q. Ding, and L. Wang, "Non-darcy flow seepage characteristics of saturated broken rocks under compression with lateral constraint," International Journal of Mining Science and Technology, vol. 26, no. 6, pp. 1145-1151, 2016.

[20] S. Ou, L. Wang, P. Wang, Z. Wang, J. Huang, and D. Zhou, "Numerical analysis of seepage flow characteristic of collapse pillar under the influence of mining," International Journal of 
Mining Science and Technology, vol. 23, no. 2, pp. 237-244, 2013.

[21] Ji Xiong, Yu Zhang, N. Zhou, and M. Li, "Pore pressure evolution and mass loss of broken gangue during the seepage," Royal Society open science, vol. 5, no. 10, Article ID 180307, 2018.

[22] L. Wang, Z. Chen, H. Kong, and X. Ni, “An experimental study of the influence of seepage pressure and initial porosity on variable mass seepage for broken mudstone," Journal of Mining \& Safety Engineering, vol. 31, no. 3, pp. 462-468, 2014.

[23] A. V. Garcia, R. M. Rached, and J. C. Santamarina, "Largescale true triaxial apparatus for geophysical studies in fractured rock," Geotechnical Testing Journal, vol. 41, Article ID 20170144, no. 4, pp. 821-829, 2018.

[24] G. Zhou, L. Qiu, W. Zhang, and J. Xue, "Simulation analysis on water's micro seepage laws under different pressure gradients using computed tomography method," Advances in Civil Engineering, vol. 2018, Article ID 3401341, pp. 1-26, 2018.

[25] L. Shi and R. N. Singh, "Study of mine water inrush from floor strata through faults," Mine Water and Environment, vol. 20, no. 3, pp. 140-147, 2001.

[26] W. Gang, W. Pengfei, G. Yangyang, and W. Li, "A novel true triaxial apparatus for testing shear seepage in gas-solid coupling coal," Geofluids, vol. 2018, Article ID 2608435, pp. 1-9, 2018.

[27] W. Du, Y. Zhang, X. Meng, W. Zhang, and W. Li, "Deformation and seepage characteristics of gas-containing coal under true tri-axial stress," Arabian Journal of Geosciences, vol. 11, no. 9, 2018.

[28] D. Ma, M. Rezania, H.-S. Yu, and H.-B. Bai, "Variations of hydraulic properties of granular sandstones during water inrush: effect of small particle migration," Engineering Geology, vol. 217, pp. 61-70, 2017.

[29] L Bo, Y. Liang, L. Zhang, and Q. Zou, "Breakage law and fractal characteristics of broken coal and rock masses with different mixing ratios during compaction," Energy Science \& Engineering, vol. 7, no. 3, pp. 1000-1015, 2019.

[30] Z. Kai, Z. Boyang, L. Jiangfeng, D. Ma, and H. Bai, "Experiment on seepage property and sand inrush criterion for granular rock mass," Geofluids, vol. 2017, pp. 1-10, 2017.

[31] E. Celik and L. Hoang, "Maximum estimates for generalized forchheimer flows in heterogeneous porous media," Journal of Differential Equations, vol. 262, no. 3, Article ID 9352618, 2017.

[32] B. Zhang and Z. Lin, "A computing method for sand inrush quantity through a borehole in Longde coal mine," Advance of Civil Engineering, vol. 2018, Article ID 4842939, 11 pages, 2018.

[33] S. J. Peng, J. Xu, H. W. Yang, and D. Liu, "Experimental study on the influence mechanism of gas seepage on coal and gas outburst disaster," Safety Science, vol. 50, no. 4, pp. 816-821, 2012.

[34] W. Zhu, Q. Qi, Q. Ma, J. Deng, M. Yue, and Y. Liu, "Unstable seepage modeling and pressure propagation of shale gas reservoirs," Petroleum Exploration and Development, vol. 43, no. 2, pp. 285-292, 2016.

[35] M. Li, J. Zhang, W. Zhang, A. Li, and W. Yin, "Experimental investigation of water-inrush risk based on permeability evolution in coal mine and backfill prevention discussion," Geofluids, vol. 2019, Article ID 3920414, pp. 1-9, 2019.

[36] Z. Zhou, X. Cai, D. Ma et al., "Water saturation effects on dynamic fracture behavior of sandstone," International
Journal of Rock Mechanics and Mining Sciences, vol. 114, pp. 46-61, 2019.

[37] C. Yong and L. Biao, "New exact travelling wave solutions for generalized zakharov-kuzentsov equations using general projective riccati equation method," Communications in Theoretical Physics, vol. 41, no. 1, pp. 1-6, 2004.

[38] H. Hua, J. Yudang, and Z. Jinmei, "Some special types of multisolution of the modified kadomtsev-petviashvili equation," Communication in Theoretical Dhysics, vol. 40, no. 3, pp. 262-264, 2003. 